\title{
Comment on "Urinary incontinence during pregnancy: prevalence, experience of bother, beliefs, and help-seeking behavior"
}

\author{
Serveh Parang ${ }^{1,2} \cdot$ Kamyar Mansori $^{3}$ \\ Received: 18 July 2021 / Accepted: 20 July 2021 / Published online: 1 October 2021 \\ (C) The International Urogynecological Association 2021, corrected publication 2022
}

\begin{abstract}
Dear Editor-in-Chief
I read with great interest the article written by Heidi F. A. Moossdorff-Steinhauser et al. [1]. The aim of this study was to determine the prevalence of self-reported UI, level of experience of bother, and beliefs to gain a greater understanding of help-seeking behavior in adult pregnant women [1]. Although this study is an interesting and valuable research work, in order to reduce misinterpretation, a number of methodological points should be considered when interpreting the results, as follows:
\end{abstract}

1. In this study, considering that the questionnaire of helpseeking behavior is researcher-made and has no dimensions, it was much better to use exploratory factor analysis (EFA) to determine the dimensions and the questions were designed based on the Likert scale. In EFA, the researcher has no previous basis for categorizing questions into different dimensions. In fact, the questions are entered into the analysis and then the statistical analysis software itself decides the dimensions in which the questions should be placed. In other words, the application of EFA is greater in new research that does not have a preconceived theory $[2,3]$.

2. The second point in the present study is the lack of attention to collinearity between questions. Collinearity, indeed, correlation between predictor variables (or independent variables), such that they express a linear relationship

Kamyar Mansori

kamyarmansori@yahoo.com

1 Clinical Care Research Center, Research Institute for Health Development, Kurdistan University of Medical Sciences, Sanandaj, Iran

2 Faculty of Nursing and Midwifery, Kurdistan University of Medical Sciences, Sanandaj, Iran

3 Department of Biostatistics and Epidemiology, School of Medicine, Zanjan University of Medical Sciences, Zanjan, Iran in a regression model when predictor variables in the same regression model are correlated, cannot independently predict the value of the dependent variable $[4,5]$.

3. The third point that needs to be mentioned is not using univariate and multivariate regression models to control confounding variables. In regression models, in order to eliminate potential confounding variables, the variables with $p$ value $\leq 0.20$ in the univariate regression model were introduced into the multivariate regression model, simultaneously. However, in the present study, researchers have studied the relationship between variables as a univariate and have not paid attention to the control of confounding variables by the multivariate regression models [6].

\section{Declarations}

Competing interests The authors have no conflicts of interest associated with the material presented in this paper.

\section{References}

1. Moossdorff-Steinhauser HF, Berghmans BC, Spaanderman ME, Bols EM. Urinary incontinence during pregnancy: prevalence, experience of bother, beliefs, and help-seeking behavior. Int Urogynecol J. 2021;32(3):695-701.

2. Fabrigar LR, Wegener DT. Exploratory factor analysis: Oxford University Press; 2011.

3. Taherdoost H, Sahibuddin S, Jalaliyoon N. Exploratory factor analysis; concepts and theory. Athens: WSEAS; 2014.

4. Hill RC, Adkins LC. Collinearity. A companion to theoretical econometrics. 2001:257-78.

5. Mason CH, Perreault WD Jr. Collinearity, power, and interpretation of multiple regression analysis. J Mark Res. 1991;28(3):268-80.

6. Kim K, Timm N. Univariate and multivariate general linear models: theory and applications with SAS. Boca Raton: CRC Press; 2006.

Publisher's note Springer Nature remains neutral with regard to jurisdictional claims in published maps and institutional affiliations. 